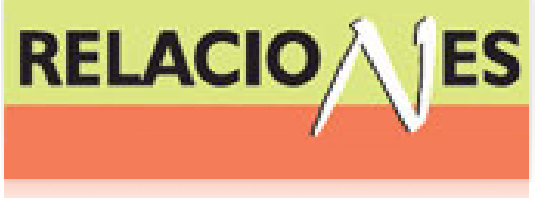

Relaciones. Estudios de historia y sociedad ISSN: 0185-3929

relacion@colmich.edu.mx

El Colegio de Michoacán, A.C

México

Miño Grijalva, Manuel

Las dimensiones productivas de los obrajes de Puebla y México en 1597

Relaciones. Estudios de historia y sociedad, vol. XXXIV, núm. 134, 2013, pp. 195-208

El Colegio de Michoacán, A.C

Zamora, México

Disponible en: http://www.redalyc.org/articulo.oa?id=13726972006

Cómo citar el artículo

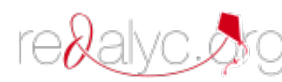

- Número completo

- Más información del artículo

Página de la revista en redalyc.org

Sistema de Información Científica

Red de Revistas Científicas de América Latina, el Caribe, España y Portugal Proyecto académico sin fines de lucro, desarrollado bajo la iniciativa de acceso abierto 
Notas y DEbATES

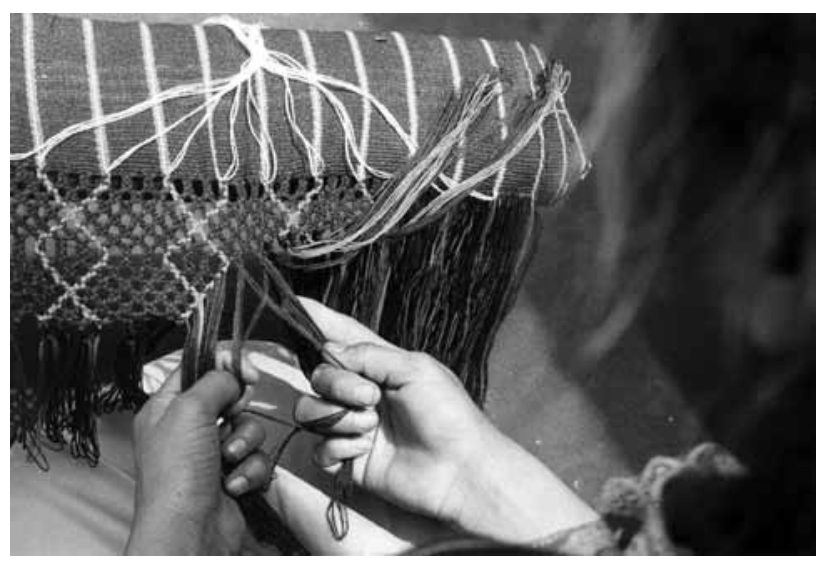





\title{
Las dimensiones productivas de los obrajes de Puebla y México en 1597
}

\author{
Manuel Miño Grijalva* \\ EL COLEGIO DE MÉXICO
}

Este artículo ofrece una visión de las dimensiones productivas de los obrajes de Puebla y la ciudad de México para finales del siglo Xvi, tomando como fuente principal una "Relación" de obrajes que da cuenta de los obrajeros que existían en las ciudades de Puebla y México -con sus alrededores-, el número de telares que disponían y los diversos géneros textiles que trabajaban en ellos, paños, bayetas y sayales, finos o comunes. Es una fotografía de su composición, porque finalmente es sólo para un año, pero su valor radica en que las estimaciones productivas van acompañadas de los precios de mercado.

(Obrajes, producción, obrajeros)

1 análisis sobre la producción es uno de los capítulos más obscuros de la historia de la producción textil obrajera mexicana e hispanoamericana en general, por lo que vale la pena abordarlo nuevamente, esta vez con el pretexto de la existencia de un documento antes visto pero no analizado suficientemente. ${ }^{1}$ Es una "Relación" de obrajes elaborada al caer el siglo xvi y da cuenta de los obrajeros que existían en las ciudades de Puebla y México -con sus alrededores-, el número de telares que disponían y los diversos géneros textiles que trabajaban en ellos, paños, bayetas y sayales, finos o comunes. ${ }^{2}$ Es una fotografía de su composición, porque finalmente

*mmino@colmex.mx

${ }^{1}$ Un primer acercamiento fue realizado por José Ignacio Urquiola Distribución geográfica de los obrajes y su volumen de producción”, en Carmen Viquiera y José Ignacio Urquiola, Los obrajes en la Nueva España, 1530-1630, México, Consejo Nacional para la Cultura y las Artes, 1990, 131-188.

${ }^{2}$ Archivo General de Indias, AGI, México 23, núm. 86e. El documento se lo debo a Luis Alonso Álvarez, a quien le expreso mi gratitud. 
es sólo para un año, pero su valor radica también en que las estimaciones productivas van acompańadas de los precios de mercado, por vara y por localidad, con lo cual podemos acercarnos confiadamente a diversas estimaciones, una de las cuales, la más importante, es poder establecer la debida jerarquía de los obrajeros poblanos.

El panorama de la industria textil en su conjunto lo podemos obtener de la Relación del Marqués de Montesclaros de 1604, tiempo suficientemente cercano como para obtener una idea clara del sector en relación con 1597 sin distorsiones pronunciadas. La ciudad de México y sus alrededores mantenía un total de 35 obrajes de paños (diez estaban dedicados a la producción de sombreros); Xochimilco aparecía con cuatro obrajes; Tacuba con dos y se menciona su existencia en Coyoacán y Cuautitlan. Es importante la presencia de ocho obrajes en Texcoco; trece en Tlaxcala; seis en Cholula; Celaya con cuatro y apenas se citan a Tecamachalco, Querétaro, Atlixco y Cuazindeo.

En el universo de la fuente constan 34 obrajeros, poseedores de 215 telares que indistintamente trabajaban los siguientes tipos de tejidos de lana en Puebla. ${ }^{3}$

Tipo de tejidos por obraje (Puebla)

\begin{tabular}{lc}
\hline & obrajes \\
\hline Bayetas/sayales & 2 \\
Paños com./sayales finos & 1 \\
Paños coms/ bayetas & 1 \\
Paños finos, coms./ sayales & 2 \\
Paños finos comuns. / sayales com. & 2 \\
Paños coms. / bayetas & 1 \\
Paños finos y comunes & 16 \\
Paños comunes & 9 \\
Total & 34 \\
\hline
\end{tabular}

${ }^{3}$ En 1604, Puebla figuraba en la Relación de Montesclaros con 35 obrajes. Albi Romero, $1970,135$. 
Sin duda predominaba la manufactura de tejido "diez y ochenos" o comunes -que habrán tenido 1,800 hilos-y no llegaban a la categoría de tejidos anchos, que eran los paños finos o veinticuatrenos. Los telares para estos tejidos constituían 65\% del total. Casi $20 \%$ se dedicaban a los tejidos finos. Los restantes porcentajes corresponden a telares dedicados a tejidos que por lo general estaban dedicados a las órdenes religiosas que tenían entre 800 y 1200 hilos. Eran los sayales comunes el tipo predominante.

Géneros de tejidos y tipos de telares (Puebla)

Telares para paños finos

Telares para pańos comunes

Telares para bayetas

Telares para sayales finos

Telares para sayales comunes

Total

Fuente: José Ignacio Urquiola "Distribución geográfica de los obrajes y su volumen de producción", p. 135.

En consonancia con la composición de los instrumentos, las dimensiones de la producción fueron acordes con un claro predominio de telares destinados a la producción de pańos comunes con $75 \%$ del total, dejando apenas $11 \%$ a telares para pańos finos. Lo que es importante anotar es que el número de operarios variaba mucho de obraje a obraje. Para tiempos distintos, por ejemplo, el obraje de Viruega funcionaba con 117 trabajadores en 1583, en el otro extremo, en 1610, el obraje de Alonso Gómez funcionaba con $257 .^{4}$

Lamentablemente no contamos con las asignaciones y contratación de operarios, pero asignando el número de seis personas por

\footnotetext{
${ }^{4}$ Pohl, Haenisch y Loske, “Aspectos sociales”, 1978, 42. Carabarín, 1984, 18.
} 
telar-que sabemos para otros tiempos- la fuerza de trabajo pudo sobrepasar los 1,300 operarios que producían anualmente las siguientes cantidades de tejidos al año.

Producción de tejido, 1597 (Puebla)

\begin{tabular}{lrc}
\hline Géneros & Piezas & Varas \\
\hline Paños finos & 410 & 14,350 \\
Paños comunes & 2,790 & 111,600 \\
Bayetas & 300 & 9,000 \\
Sayales finos & 70 & 8,400 \\
Sayales comunes & 144 & 17,280 \\
Total & 3,714 & 160,630 \\
\hline
\end{tabular}

De todas formas en Segovia no había obrajes, por lo que la comparación resulta poco apropiada, necesitaríamos información del espacio andino para una comparación más ajustada a las condiciones novohispanas. De todas formas, por cada telar la producción no pasaba de las 75 varas a la semana, constituyendo las bayetas y los sayales los géneros de mayor manufactura y realización.

Producción por telar anual (Puebla)

\begin{tabular}{lc}
\hline Géneros & Varas \\
\hline Paños finos & 350 \\
Paños comunes & 297 \\
Bayetas & 600 \\
Sayales finos & 1,200 \\
Sayales comunes & 1,440 \\
Total & 3,887 \\
\hline
\end{tabular}


En comparación con otras realidades posiblemente no es gran cosa las dimensiones productivas de la industria poblana, pero podría representar una buena fuente de ingresos si calculamos el valor monetario de sus tejidos, de acuerdo a lo que puede verse en el cuadro siguiente:

Valor de la producción textil (Puebla)

\begin{tabular}{lrc}
\hline Géneros & \multicolumn{1}{c}{ Reales } & $(\%)$ \\
\hline Paños finos & 215,250 & 18.60 \\
Paños comunes & 837,000 & 72.33 \\
Bayetas & 49,500 & 4.27 \\
Sayales finos & 29,400 & 2.54 \\
Sayales comunes & 25,920 & 2.26 \\
Total & $1,157,070$ & 100 \\
\hline
\end{tabular}

Nuevamente los paños comunes representan el rubro más importante con $72 \%$ seguido por los pańos finos, por lo que en consonancia con esto la producción por telar sigue la mismas proporciones, aunque es notablemente más cercana dado el mayor costo de los paños finos y se acerquen los sayales finos y comunes por su mayor cantidad.

Valor de la producción por telar (Puebla)

\begin{tabular}{ll}
\hline Géneros & Reales \\
\hline Paños finos & 5,250 \\
Paños comunes & 5,978 \\
Bayetas & 3,300 \\
Sayales finos & 4,200 \\
Sayales comunes & 2,160 \\
\hline
\end{tabular}


La dimensión económica del sector posiblemente puede ser obtenida de los cómputos totales que las varas tejidas arrojan a precio de venta. Los obrajeros, que por el número de piezas y varas tejida a precios del mercado obtenían los mayores ingresos, estuvieron encabezados por Alonso Gómez, quien aparecía como el mayor productor de tejidos con un ingreso -no utilidad- de 77,820 reales. En el rango de los 60 mil reales aparecen Hernando del Castillo con 69,750, Agustín Meléndez con 64,200 y Juan García Barranco con 63,750 reales. En el rango de los cincuenta mil se consigna a Cristóbal Barreiro con 54,750 y en el rango de los cuarenta mil Gabriel de Angulo con 47,910 reales, Francisco Ligero con 47,250, Miguel Hernández S. con 46,500, Antón del Río 42,000, Gaspar de Rojas y Salvador Martínez con 40,500 cada uno. Todos estos ingresos representan 52 por ciento de un gran total de 1,139,070 reales o 142,383 pesos. El que más ingresos obtuvo, Gómez no llegaba a los $10 \mathrm{mil}$ pesos anuales. $48 \%$ restante había recibido ingresos por cantidades que iban de los 28,500 reales a 8,160, equivalentes, éstos, a 1,020 pesos. Evidentemente, para poder calcular las utilidades habría que complicar los cálculos con los costos de producción.

Los obrajeros que constan en la relación, de alguna manera corresponden a la segunda generación de obrajeros que llegaron a Puebla desde Brihuega. Por ejemplo, Gabriel de Angulo es hijo de Andrés de Angulo, y en el mismo año de 1597 es ya capitán y tesorero de la Santa Cruzada y poco después ingresará al Cabildo de la ciudad. ${ }^{5}$ Desde antes, 1592, Rodrigo García, Alonso Gómez, además de Angulo compraron el nombramiento de regidores por 4,000; 4,$600 ;$ y 4,000 pesos respectivamente, aunque el Cabildo poblano no aceptó su incorporación, dado que la ley no permitía que quienes fueran propietarios de telares desempeñaran dicho puesto. Así, los herederos de los aristocráticos conquistadores mostraban su resistencia a admitir nuevos ricos y advenedizos. ${ }^{6}$ Pero hecha la ley hecha la trampa, pues Gómez, García y Angulo vendieron sus obrajes para

${ }^{5}$ Guadalupe Albi Romero, "La sociedad de Puebla de los Ángeles en el siglo xvi”, en Jabrbuch, T./, p. 132.

${ }^{6}$ Albi Romero, "La sociedad...", pp. 142-143. 
ingresar al cuerpo edilicio, sin embargo, esta venta resulta ser ficticia, pues la Relación de 1597 que analizamos demuestra que no fue así y no vendieron nada, pues constan como sus propietarios.

En el caso de la ciudad de México, las dimensiones productivas eran menores que las poblanas, aunque producían únicamente paños finos y comunes. El cuadro muestra que en total los primeros no llegaban a producir las 7 mil varas y los segundos no alcanzaban las 40 mil.

Producción de los obrajes de México (1597)

\begin{tabular}{lcccccr}
\hline Obrajeros & \multicolumn{2}{c}{ P. Comunes } & & \multicolumn{2}{c}{ P. Finos } \\
\cline { 2 - 3 } \cline { 5 - 6 } & (Piezas) & Varas & & (Piezas) & Varas \\
\hline Juan Álvarez & 300 & 11,400 & & 30 & 1,140 \\
Juan Altamirano & 300 & 11,400 & & 25 & 950 \\
Matías de Blanca & 200 & 7,600 & & 20 & 760 \\
Melchor de Pastrana & & & & 50 & 1,900 \\
Juan Bautista Martínez & 200 & 7,600 & & 25 & 950 \\
Juan de la Fuente & & & & 30 & 1,140 \\
Total & 1,000 & 38,000 & & 180 & 6,840 \\
Cada pieza tenía 38 varas & & & & & \\
\hline
\end{tabular}

Juan Álvarez y Juan Altamirano eran los principales obrajeros de la ciudad de México y los alrededores: San Jerónimo, Azcapotzalco y Tezmelucan. De todas formas sus ingresos son 7,267 pesos en el primer caso y 6,270 en el segundo.

Valor de la producción de los obrajes de México

\begin{tabular}{lccc}
\hline Obrajeros & $\begin{array}{c}\text { P. Comunes } \\
\text { reales* }^{*}\end{array}$ & $\begin{array}{c}\text { P. Finos } \\
\text { reales }^{* *}\end{array}$ & $\begin{array}{c}\text { Total } \\
\text { reales }\end{array}$ \\
\hline Juan Álvarez & 21,660 & 36,480 & 58,140 \\
Juan Altamirano & 21,660 & 28,500 & 50,160 \\
Matías Blanca & 144,400 & 1,435 & 145,835
\end{tabular}


Valor de la producción de los obrajes de México (continuación)

\begin{tabular}{lcrc}
\hline Obrajeros & $\begin{array}{c}\text { P. Comunes } \\
\text { reales }\end{array}$ & $\begin{array}{c}\text { P. Finos } \\
\text { reales } * *\end{array}$ & \multicolumn{1}{c}{$\begin{array}{c}\text { Total } \\
\text { reales }\end{array}$} \\
\hline Melchor de Pastrana & & 24,320 & 24,320 \\
Juan B. Martínez & 144,400 & 28,500 & 172,900 \\
Juan de la Fuente & & 36,480 & 36,480 \\
S27,060 & 155,715 & 682,775 \\
\hline
\end{tabular}

* Los pańos comunes se han calculado a 19 reales la vara.

** Los pańos finos, su precio se ha calculado a 32 reales.

\section{Conclusiones}

De lo anterior se desprende que es posible que se haya exagerado el hecho de que Puebla producía principalmente paños finos para esta época, pues los porcentajes de paños, bayetas y sayales comunes dominan la dimensión económica textil para ese espacio y ese tiempo. Es decir, si juntamos los diversos tipos, casi $90 \%$ estuvo dedicado a la producción de paños comunes o angostos. Más de 160,000 varas por año no parece una cifra despreciable, aunque era menor comparada con lugares como Segovia. ${ }^{7}$

\footnotetext{
${ }^{7}$ Urquiola, p. 136.
} 


\section{Anexo}

$1597^{8}$

Relación de los obrajes que se hallaron en la ciudad de los Ángeles por el mes de junio de mil y quinientos y noventa y siete años y los telares que cada obraje trae y los paños finos y paños comunes qu llaman diez y ochenos, bayetas y sayales que se hacen en ellos en todo un año

\begin{tabular}{|c|c|c|c|c|c|c|}
\hline Obrajeros & Telares & $\begin{array}{l}\text { Paños } \\
\text { Finos }\end{array}$ & $\begin{array}{l}\text { Paños } \\
\text { 18nos }\end{array}$ & Bayetas & $\begin{array}{l}\text { Sayales } \\
\text { Finos }\end{array}$ & $\begin{array}{l}\text { Sayales } \\
\text { Comunes }\end{array}$ \\
\hline Melchor Rodríguez & 5 & & & 40 & 30 & \\
\hline $\begin{array}{l}\text { La viuda de G García } \\
\text { Barranco }\end{array}$ & 5 & 20 & 60 & & & \\
\hline $\begin{array}{l}\text { Gaspar de Rojas } \\
\text { Victoria }\end{array}$ & 7 & 20 & 100 & & & \\
\hline Gabriel de Angulo & $9^{9}$ & 30 & 100 & & & 12 \\
\hline Pedro de Alcanadre & 7 & 10 & 100 & & & 12 \\
\hline Sabastían Tomellín & 7 & & 120 & & & 12 \\
\hline Martín de la Fuente & 5 & & 100 & & & \\
\hline Agustin Meléndez & 11 & & 200 & & 10 & \\
\hline Francisca del Castillo & 2 & & 40 & & & \\
\hline $\begin{array}{l}\text { Miguel Hernández } \\
\text { Salmoral }\end{array}$ & 8 & 20 & 120 & & & \\
\hline Julio de Ortega & 5 & & 60 & 40 & & \\
\hline Crisdtóbal Varreiro & 10 & 70 & 60 & & & \\
\hline Bartolomé de la Torre & 6 & 20 & 40 & & & 24 \\
\hline Alonso Gómez & 13 & 60 & 140 & & & 24 \\
\hline Juan García Barranco & 13 & 30 & 160 & & & \\
\hline Pedro de Hita & 5 & & 60 & 40 & & \\
\hline Antón del Río & 7 & & 140 & & & \\
\hline
\end{tabular}


(Continuación)

\begin{tabular}{|c|c|c|c|c|c|c|}
\hline Obrajeros & Telares & $\begin{array}{l}\text { Paños } \\
\text { Finos }\end{array}$ & $\begin{array}{l}\text { Paños } \\
\text { 18nos }\end{array}$ & Bayetas & $\begin{array}{l}\text { Sayales } \\
\text { Finos }\end{array}$ & $\begin{array}{l}\text { Sayales } \\
\text { Comunes }\end{array}$ \\
\hline Rodrigo García & $6^{10}$ & & 120 & & & \\
\hline Francisco Lixero & 8 & 10 & 140 & & & \\
\hline Salvador Martínez & 7 & 20 & 100 & & & \\
\hline Cristóbal de Viruega & 5 & 20 & 60 & & & \\
\hline Hernando de Pastrana & 5 & 10 & 80 & & & \\
\hline Andrés Bermejo & 3 & & 60 & & & \\
\hline Gaspar de Fuas & 4 & & 80 & & & \\
\hline $\begin{array}{l}\text { Antonio Martínez } \\
\text { Canas }\end{array}$ & 5 & 20 & 60 & & & \\
\hline Hernando del Castillo & 12 & 30 & 180 & & & \\
\hline Miguel Pérez & 4 & & 40 & & & 24 \\
\hline Matías de Landeta & 4 & & 80 & & & \\
\hline Lucas de Rivas & 2 & & 20 & & & 12 \\
\hline Melchor de Ortega & 5 & 20 & 60 & & & \\
\hline Juan García Carrillo & 5 & & & 40 & 30 & \\
\hline Miguel González & 4 & & 20 & 20 & & 24 \\
\hline Francisco de Velasco & 7 & & 10 & 120 & & \\
\hline Blas Rojas & 4 & & 80 & & & \\
\hline Total & 215 & $410^{*}$ & $2790^{* *}$ & $300^{* * *}$ & 70 & 36 \\
\hline
\end{tabular}

${ }^{10}$ En 1593 mantenía 8 telares. Idem. ${ }^{*}$ En el original se consigna $420 .{ }^{* *}$ En el original la suma es de $2,900 .{ }^{* * *}$ En el original la suma es de 180 .

Las varas que tiene cada paño: paño fino 35; 18nos. 40; bayetas 30; sayales finos y bastos 120 .

Parece haberse hallado en la ciudad de los Ángeles por el mes de junio de noventa y siete ańos treinta y cuatro obrajeros que traen 215 telares y hacen en ellos cuatrocientos y veinte paños finos, dos mil novecientos paños comunes diez y ochenos, ciento ochenta bayetas, setenta sayales finos y ciento y cuarenta y cuatro sayales comunes. El 
valor desta rropa de presente es de cuatro" [sic] pesos. La vara de los pańos finos a quince reales; los diez y ochenos a siete reales y medio. Las bayetas a cinco reales y medio; los sayales finos a tres reales y medio; los comunes. Pero lo que ordenanza mediante suele correr es a tres pesos y medio. Los paños finos a trece reales; los diez y ochenos a cinco reales y medio; los sayales finos a siete reales; las bayetas a tres reales los sayales comunes [sic]

Relación de los Paños que se labran en México y su comarca. Responde al capítulo 17 de la carta de gobierno.

Relación de los Paños que de ordenanzas se labran en México y su comarca y a los precios que suelen valer. Responde al capitulo 17 de la carta de gobierno

-A Juan Álvarez en dos obrajes que tiene hace cada año trecientos paños diez y ochenos y treinta veinte y cuatreños. La vara de los diez y ochenos suele vender diez y ocho reales y medioy a diez y nueve, y los veinte y cuatreńos a cuatro pesos y dos tomines y a cuatro y medio.

-En el obraje de don Juan Altamirano se hacen otros trecientos pańos diez y ochenos y veinte y cinco veinte y cuatreños. La vara de los diez y ochenos a a diez y ocho reales y de los veinte y cuatreños a treinta reales.

-Matías de Banca, en Tezmeluca, tres leguas de México cada año ducientos pańos $\mathrm{y}$ veinte $\mathrm{y}$ cuatreños veinte, $\mathrm{y}$ al mesmo precio que Juan Álvarez.

-Melchor de Pastrana en México, cincuenta paños [al año] a diez y seis reales la vara.

-Juan Bautista Martínez, junto a San Gerónimo, tres leguas de México [labra al año] ducientos paños y veinte y cinco veinte y cuatreños al mismo precio que Juan Álvarez

-Juan de la Fuente en Azcaposalco [labra al año] treinta paños a diez y seis reales vara

Y todos estos paños tienen unos con otros a treinta y ocho varas. $\mathrm{Al}$ margen: Relación de los Paños que se labran en México y su comarca. Responde al capítulo 17 de la carta de gobierno. 


\begin{tabular}{|c|c|c|c|c|c|c|}
\hline Obrajeros & $\begin{array}{l}\text { Paños } \\
\text { Finos }\end{array}$ & $\begin{array}{l}\text { Paños } \\
\text { 18nos }\end{array}$ & Vayetas & $\begin{array}{l}\text { Sayales } \\
\text { Finos }\end{array}$ & $\begin{array}{c}\text { Sayales } \\
\text { Comu- } \\
\text { nes }\end{array}$ & $\begin{array}{l}\text { Total } \\
\text { (reales) }\end{array}$ \\
\hline Melchor Rodríguez & & & 4,200 & 12,600 & & 16,800 \\
\hline $\begin{array}{l}\text { La viuda de Bartolomé } \\
\text { García Barranco }\end{array}$ & 10,500 & 18,000 & & & & 28,500 \\
\hline Gaspar de Rojas Victoria & 10,500 & 30,000 & & & & 40,500 \\
\hline Gabriel de Angulo & 15,750 & 30,000 & & & 2,160 & 47,910 \\
\hline Pedro de Alcanadre & 5,250 & 30,000 & & & 2,160 & 37,410 \\
\hline Sabastían Tomellín & & 36,000 & & & 2,160 & 38,160 \\
\hline Martín de la Fuente & & 30,000 & & & & \\
\hline Agustin Meléndez & & 60,000 & & 4,200 & & 64,200 \\
\hline Francisca del Castillo & & 12,000 & & & & 12,000 \\
\hline $\begin{array}{l}\text { Miguel Hernández } \\
\text { Salmoral }\end{array}$ & 10,500 & 36,000 & & & & 46,500 \\
\hline Julio de Ortega & & 18,000 & 4,200 & & & 22,200 \\
\hline Crisdtóbal Va? & 36,750 & 18,000 & & & & 54,750 \\
\hline Bartolomé de la Torre & 10,500 & 12,000 & & & 4,320 & 26,820 \\
\hline Alonso Gómez & 31,500 & 42,000 & & & 4,320 & 77,820 \\
\hline Juan García Barranco & 15,750 & 48,000 & & & & 63,750 \\
\hline Pedro de Hita & & 18,000 & 4,200 & & & 22,200 \\
\hline Antón del Río & & 42,000 & & & & 42,000 \\
\hline Rodrigo García & & 36,000 & & & & 36,000 \\
\hline Francisco Ligero & 5,250 & 42,000 & & & & 47,250 \\
\hline Salvador Martínez & 10,500 & 30,000 & & & & 40,500 \\
\hline Cristóbal de Vinueza & 10,500 & 18,000 & & & & 28,500 \\
\hline Hernando de Pastrana & 5,250 & 24,000 & & & & 29,250 \\
\hline Andrés Bermejo & & 18,000 & & & & 18,000 \\
\hline
\end{tabular}


(Continuación)

\begin{tabular}{|c|c|c|c|c|c|c|}
\hline Obrajeros & $\begin{array}{l}\text { Paños } \\
\text { Finos }\end{array}$ & $\begin{array}{l}\text { Paños } \\
\text { 18nos }\end{array}$ & Vayetas & $\begin{array}{c}\text { Sayales } \\
\text { Finos }\end{array}$ & $\begin{array}{c}\text { Sayales } \\
\text { Comu- } \\
\text { nes }\end{array}$ & $\begin{array}{c}\text { Total } \\
\text { (reales) }\end{array}$ \\
\hline Gaspar de Fuas? & & 24,000 & & & & 24,000 \\
\hline Antonio Martínez Canas & 10,500 & 18,000 & & & & 28,500 \\
\hline Hernando del Castillo & 15,750 & 54,000 & & & & 69,750 \\
\hline Miguel Pérez & & 12,000 & & & 4,320 & 16,320 \\
\hline Martín de Landeta & & 24,000 & & & & 24,000 \\
\hline Lucas de R.? & & 6,000 & & & 2,160 & 8,160 \\
\hline Melchor de Ortega & 10,500 & 18,000 & & & & 28,500 \\
\hline Juan García Carrillo & & & 4,200 & 12,600 & & 16,800 \\
\hline Miguel González & & 6,000 & 2,100 & & 4,320 & 12,420 \\
\hline Francisco de Velasco & & 3,000 & 12,600 & & & 15,600 \\
\hline Blas Rojas & & 24,000 & & & & 24,000 \\
\hline Total & 215,250 & 837,000 & 31,500 & 29,400 & 25,920 & $1,139,070$ \\
\hline
\end{tabular}

Fuentes

Archivos

Archivo General de Indias (AGI)

AGI, México 23, núm. 86e

BiBLIOGRAFÍA

Albi Romero, Guadalupe, "La sociedad de Puebla de los Ángeles en el siglo XVI", en Jahrbuch für Geschichte Lateinamerikas, t. 7, 1970, 76-145.

Carabarín Gracia, Alberto, El trabajo y los trabajadores del obraje en la ciudad de Puebla, 1700-1710, Puebla, Universidad Autónoma de Puebla, 1984. 
Pohl, Hans, Jurra Haenish y Wolfgang Loske, "Aspectos sociales del desarrollo de los obrajes textiles en Puebla colonial", en Comunicaciones. Proyecto Puebla-Tlaxcala, núm. 15, Puebla 1978.

URQuiola, José Ignacio, “Distribución geográfica de los obrajes y su volumen de producción”, en Carmen Viquiera y José Ignacio Urquiola, Los obrajes en la Nueva España, 1530-1630, México, Consejo Nacional para la Cultura y las Artes, 1990, 131-188. 